\title{
O DESAFIO DA CLÍNICA PSICANALÍTICA COM IDOSOS
}

\author{
José Tiago dos Reis Filho* \\ Gisela de Carvalho Santos**
}

Resumo

O texto narra uma experiência de atendimento psicoterapêutico de referência psicanalítica de um sujeito idoso, realizada durante o estágio de uma estudante de graduação em Psicologia. A velhice, enquanto categoria, é aqui discutida, enfatizando seus aspectos sociais e psíquicos. Articular os conceitos de velhice, doença, clínica psicanalítica e multidisdiplinaridade foi um desafio apresentado à jovem terapeuta e seu supervisor psicanalista. Dessa forma, partimos do conceito de clínica ampliada e elaboramos uma crítica ao atual sistema de saúde, que oferece um atendimento precário a seus usuários e, principalmente, à população idosa, que tem crescido cada vez mais.

Palavras-chave: velhice, psicanálise, clínica ampliada, multidisciplinaridade

\section{Abstract}

\section{THE CHALLENGE OF PSYCHOANALYTIC CLINIC WITH ELDERLY INDIVIDUALS}

This article recounts the experience of an elderly individual's psychotherapeutic treatment that was carried out, with supervision, by a psychology undergraduate student. Old age, as a category, is here discussed, emphasizing its social features as well as psychological aspects. The articulation of concepts such as old age, illness, clinical psychoanalysis and multidisciplinarity, was a challenge presented to the young therapist and her supervisor. In face of that, starting from the concept of extended clinic, we developed a critique of the current health system, which offers precarious support to its users, especially to the elderly population, that is rapidly expanding. Keywords: oldness, psychoanalysis, extended clinical, multidisciplinarity

* Psicanalista; Doutor em Psicologia Clínica pela Pontifícia Universidade Católica de São Paulo e Professor da Pontifícia Universidade Católica de Minas Gerais.

${ }^{* *}$ Graduanda em Psicologia da Pontifícia Universidade Católica de Minas Gerais / Betim. 
Freud (1898/1976), ao tratar da aplicabilidade da teoria psicanalítica, faz algumas objeçōes. Afirma que a Psicanálise não é aplicável a jovens ou adultos considerados débeis ou incultos e também fracassa com idosos, uma vez que apresentam um acúmulo de material psíquico que demandaria muito tempo para ser trabalhado, além de estarem em um período da vida ao qual nenhum valor é dado à saúde nervosa.

Passado pouco mais de um século, ainda constatam-se objeções quanto ao tratamento psicanalítico em idosos. Não raro, considera-se que as pessoas idosas apresentam determinadas características que inviabilizam o tratamento, como adesividade libidinal, isto é, dificuldade em retirar os investimentos libidinais de certos objetos, inércia psíquica e até mesmo dificuldade de simbolização.

É compreensível a objeção de Freud, num contexto em que a perspectiva de vida não ultrapassava os 40 anos. Contudo, a realidade atual difere em muitos aspectos daquela. Na contemporaneidade, o aumento da perspectiva de vida é um fato. Segundo Mucida (2004), ser idoso na atualidade é deparar-se com as mais diversas formas de desamparo, uma vez que a lógica predominante é a do mercado. Valorizam-se as novidades, a juventude, a beleza, o inovador. Neste contexto, não há espaço para o que é velho. Portanto, a velhice se torna uma questão para quem é idoso, para quem tenta não ser e também para quem virá a ser. Desta forma, que possíveis argumentos poderiam isentar a Psicanálise de se haver com o público idoso? Afinal, quem é o sujeito da prática analítica?

É sabido que o objeto de estudo da Psicanálise é o inconsciente. Ele possui uma forma peculiar de funcionamento e constituição que ignora a lógica cronológica e temporal. Seu núcleo

consiste em representantes pulsionais que procuram descarregar seu investimento; isto é, consiste em impulsos carregados de desejo. Esses impulsos são coordenados entre si, existem lado a lado sem se influenciarem mutuamente e estão isentos de contradição mútua.

Não há nesse sistema lugar para negação, dúvida ou quaisquer graus de certeza. [...] os processos inconscientes dispensam pouca atenção à realidade. Estão sujeitos ao princípio do prazer, [...] [e são também] atemporais, isto é, não são ordenados temporalmente, não se alteram com a passagem do tempo; não têm qualquer referência ao tempo (Freud, 1915/1974: 214).

A partir do objeto de estudo da Psicanálise, é possível presumir que o sujeito da prática analítica é o sujeito do inconsciente, e este não envelhece. Por esse motivo, quando Maria buscou atendimento psicológico, o fato de ter 68 anos não constituiu empecilho para dar início a seu processo analítico. 
Maria nasceu no interior de Minas, cresceu ajudando seu pai na colheita de café, tornando, assim, o trabalho um valor significativo em sua vida. Após casarse, mudou para a "cidade grande", onde teve 10 filhos. Destes, um era caminhoneiro e faleceu quando dirigia, devido a causas naturais. Seu marido trabalhava na coleta de lixo; ela, por sua vez, ficava em casa cuidando dos filhos e dos afazeres domésticos, atividades nas quais sentia muito prazer.

Aos 68 anos teve um A.V.C (Acidente Vascular Cerebral), incidente significativo em sua vida. Havia dado início ao tratamento fisioterapêutico e, por apresentar freqüentes e intensas crises de choro, foi encaminhada para tratamento psicológico no segundo semestre de 2005. Ambos tratamentos ocorreram na clínica-escola da mesma instituição.

Na primeira entrevista, Maria chegou em uma cadeira de rodas e apresentava o lado esquerdo do corpo paralisado. Estava acompanhada de seu esposo, que participou deste primeiro encontro. Ao ser indagada sobre o motivo da procura de atendimento psicológico, respondeu não estar bem da cabeça, além de não se lembrar das coisas. Seu marido foi quem relatou sobre as crises de choro, que tiveram início após o A.V.C..

Nas sessōes que se seguiram, uma demanda diferente foi se configurando. Significantes como "perda", "morte" e "trabalho" começaram a aparecer e a se repetirem em diversos fatos. Maria relatou a morte de seu filho e de seu pai, ressaltando neles a qualidade de serem trabalhadores. $\mathrm{O}$ primeiro, caminhoneiro, estava trabalhando e faleceu quando repentinamente sentiu um mal-estar, caindo do caminhão e batendo com a cabeça no chão. O segundo sempre estava envolvido nas atividades rurais; um dia, após chegar do trabalho, disse não estar se sentindo bem e pouco tempo depois teve um infarto fulminante.

Maria também relatava as conseqüências de suas perdas físicas; dizia não poder visitar seus irmãos, que moravam em outras cidades, além de não dar conta de fazer o trabalho doméstico; relatava, com certo incômodo, a necessidade de ajuda para tomar banho, se alimentar, beber água, etc.

Ao mencionar suas incapacidades e dificuldades, sempre se reportava ao A.V.C.. Alegava que, por causa dele, não podia fazer mais nada, chegou a dizer que "quanto mais velho se fica não se serve mais para nada". Apesar das autorecriminações, relatava os progressos realizados na fisioterapia e afirmou ter ficado contrariada com o fisioterapeuta que a chamou de preguiçosa.

Diante do que havia sido exposto, e levando em consideração o tempo disponível, a direção do tratamento foi no sentido de auxiliar no processo de elaboração do luto e trabalhar questões relacionadas ao significante "trabalho". 
Com relação ao luto, ficou claro que Maria não o tinha concluído. Permanecia ligada à imagem que tinha de si, antes da ocorrência do A.V.C., experimentando as lembranças dessa fase com lamentação, tristeza e dor. Freud (citado por Mucida, 2004), afirma que no processo de luto ocorre uma introversão da libido, que estava investida num determinado objeto, ao eu, ocasionando desânimo penoso, inibição das atividades e desinteresse pelo mundo externo. Assim, a conclusão desse processo é o que permite ao eu investir novamente em outros objetos.

Intervençôes que promoviam reflexões sobre as possibilidades e progressos de Maria foram realizadas com o intuito de auxiliar no processo de luto. Aos poucos ela começou a relatar que estava se vestindo e indo ao banheiro sozinha. Pequenos ganhos foram aparecendo em seu discurso, pouco a pouco o interesse pelo mundo externo foi reaparecendo, conseguiu até viajar para o "interior" a fim de ver seus irmãos.

Inúmeras vezes, a paciente demonstrou dificuldade em lidar com suas limitaçôes físicas e práticas; não conseguia pensar em uma nova forma de ser. Mucida (2004) afirma que na velhice o real da castração se impõe de forma irrevogável, uma vez que as perdas, não somente as relacionadas à imagem corporal, remetem o sujeito à fase do espelho, mas um espelho quebrado, pois, se na infância esta fase remete a uma imagem totalizante, na velhice o idoso se depara com um corpo fragmentado, despedaçado, corpo para a morte.

[Essa] vivência de despedaçamento vivida muitas vezes na velhice é, ao contrário, uma antecipação sem retorno, pois várias mudanças em curso não oferecem perspectivas de novas aquisiçōes. Ao contrário, tratando-se da imagem, são perdas que não encontram nenhuma reparação e com as quais o sujeito deverá se conformar e se adaptar (Mucida, 2004: 109).

O sujeito envelhece de forma peculiar e singular, levando em consideração a imagem que o Outro lhe devolve. As imagens devolvidas pelo Outro são tão diversificadas quanto as inúmeras possibilidades de se envelhecer. Beauvoir diz que "a velhice teria dois sentidos diferentes, uma categoria social mais ou menos valorizada segundo as circunstâncias. E para cada indivíduo, um destino singular" (Beauvoir, citado por Mucida, 2004: 28). As influências da categoria social sobre a senescência são "escolhidas" pelo próprio sujeito, de acordo com os significantes de cada um.

Ao dizer que "quanto mais velho se fica mais não se serve para nada", Maria demonstra a introjeção do discurso social. Estando inserida num contexto capitalista, no qual se valoriza sobretudo a capacidade produtiva e/ou consumista dos 
sujeitos, sofre as conseqüências de sua incapacidade para o trabalho. Por outro lado, o significante "trabalho" começou a se tornar mais freqüente quando vários fatos envolvendo seu pai foram relatados. Esta é a parte singular que o "trabalho" revela sobre Maria. Este significante está relacionado a seu Ideal de Eu, faz parte de sua constituição egóica, sendo, portanto, um traço de identificação com o pai. Abras e Sanches (2004) afirmam que

o Ideal do Ego e o Ego ideal são identificações relativas às fases do narcisismo. São identificações com o próprio Eu e com os ideais e ideologias familiares. Estas identificações se encontram abaladas no processo de envelhecimento na medida em que o sujeito se vê incapaz de corresponder a estas imagens de perfeição narcísicas (Abras \& Sanches, 2004: 5).

Maria não mais se reconhecia como aquela que trabalhava e se via cada vez mais distante da possibilidade de morrer trabalhando, assim como seu pai e seu filho. Sendo assim, as retaliações trazidas pelo olhar do Outro que desvaloriza quem não mais trabalha se tornavam bastante incisivas. As intervenções tiveram o objetivo de fazê-la refletir sobre as semelhanças e diferenças em relação a seu pai.

Em uma determinada sessão, Maria chegou dizendo que aquele seria seu último dia de terapia, pois não havia ninguém para levá-la. Este foi um momento marcante para a jovem terapeuta. Seu coração começou a bater mais rápido, a teoria e o que tinha estudado até o momento pareceram sumir por um instante. Pensou: "será que fiz algo errado? E agora, o que faço?". Apesar do "embaraço", a jovem terapeuta, levando em consideração a dificuldade de abstração apresentada por Maria, propôs uma situação problema, para que essa pudesse refletir sobre a desistência do tratamento.

O processo terapêutico havia chegado a um estágio que colocava em discussão o posicionamento de Maria no mundo. É possível dizer que, de alguma forma, a necessidade de mudança foi percebida, mas não "aceita". Mudar o estado de coisas seria abrir mão de vários ganhos secundários que estava tendo com sua postura passiva e impotente; por isso, a resistência se fez necessária.

Freud (1912/1969), no texto "A dinâmica da transferência", diz da resistência como sendo uma modalidade da transferência, podendo ocorrer para manter o estado de coisas, que foi o caso de Maria, ou porque conteúdos inconscientes se tornam vulneráveis, podendo se tornar conscientes, o que é inaceitável pela consciência. No processo analítico ocorre a introversão, isto é, a parte da libido que é direcionada à realidade, capaz de se tornar consciente, é diminuída, retornando ao eu e aumentando aquela relacionada ao inconsciente. Nesse processo, a libido 
entra em curso regressivo e revive as imagos infantis; o analista busca rastrear a libido, tornando-a consciente e útil à realidade.

No ponto em que as investigações da análise deparam com a libido retirada em seu esconderijo, está fadado a irromper um combate; todas as forças que fizeram a libido regredir se erguerão como resistências ao trabalho da análise, a fim de conservar o novo estado de coisas. [...] Mas as resistências oriundas desta fonte não são as únicas, ou, em verdade, as mais poderosas. A libido à disposição da personalidade do indivíduo esteve sempre sob a influência da atração de seus complexos inconscientes (ou mais corretamente, das partes desses complexos pertencentes ao inconsciente) e encontrou um curso regressivo devido ao fato de a atração da realidade haver diminuído. A fim de liberá-la, esta atração inconsciente tem de ser superada, isto é, o recalque das pulsões inconscientes e de suas produções, que entrementes se estabeleceu no indivíduo, deve ser removida (Freud, 1912/1969: 114).

Manobrada a resistência, Maria voltou na sessão seguinte com um novo discurso. Novos temas começaram a ser apresentados. Dizia sentir medo de estar sozinha, de ficar pensando coisas, as quais não conseguia dizer naquela hora, mas que em outro momento nomeou como medo de morrer e ninguém ver. Começou uma série de reclamações sobre o marido e também demonstrou o apego que tinha a ele; dizia não suportar sua ausência em hipótese alguma. Ao ser questionada quanto à sua relação conjugal, antes do A.V.C., ela respondeu: "No momento que a gente mais ia ficar junto eu caí". O A.V.C. ocorreu pouco tempo depois que seu marido havia se aposentado, ou seja, ele estaria mais tempo em casa, ela teria que ser objeto do desejo, e o objeto causa de desejo.

Após um período de férias, as atividades foram retomadas, e Maria já não andava mais de cadeiras de rodas, tinha agora o auxílio de uma bengala, seus movimentos físicos estavam cada vez melhores. Continuava a freqüentar a fisioterapia e a mostrar seus progressos.

Durante algumas sessões, logo após a retomada do tratamento, uma série de assuntos trabalhados no ano anterior começou a ser reeditada, por assim dizer. Falou de suas perdas físicas e de suas incapacidades, mas não de forma retaliativa como antes; da morte, agora com o diferencial de conseguir nomeá-la e dizer do medo de morrer sozinha sem ninguém ver; falou também do trabalho e do marido. Freud (1914/1969), no texto "Recordar, repetir e elaborar", explica que o recordar e o repetir são regulados pelas resistências, mas que esse é um movimento necessário para que determinados conteúdos sejam elaborados, possibilitando o aparecimento de outros. 
Tendo passado esse período de recordaçōes e repetições, Maria se deteve nas reclamações sobre o marido. A partir de então, algo estranho começou a acontecer. Às vezes ela parava de falar repentinamente, ou ficava em silêncio, de modo estranho, por um longo tempo. O que estaria acontecendo? Quando se está perante um sujeito atípico, como ela, não é possível psicologizar todos os acontecimentos. Havia momentos em que ela se levantava e andava pela sala devido a dores nas costas, às vezes sentia sede, ou mesmo sono, no meio da sessão, por causa dos fortes medicamentos administrados, outras vezes deitava a cabeça no braço do sofá por sentir cansaço físico.

Era necessário investigar sua rotina diária para entender o que estava acontecendo. Maria, após o A.V.C., caiu algumas vezes, batendo com a cabeça e, apesar disso, não havia realizado nenhum exame neurológico. Ao ser indagada sobre a existência de algum fato extraordinário, relatou que havia caído. Estava tendo crises de ausência, isto é, ficava ligeiramente inconsciente; sua língua estava enrolando, além de ter começado a sentir dores nas pernas. A partir desses relatos, a possibilidade de um novo A.V.C. foi cogitada.

Diante da complexidade dos fatos, a jovem terapeuta se dispôs a discutir o caso com a fisioterapeuta de Maria. Ao expor a situação, a fisioterapeuta pareceu não ouvir a gravidade dos acontecimentos e alegou que a paciente era poliqueixosa, não colaborava nos exercícios e sempre dizia estar com alguma dor. Pensou até em dar alta a ela. A jovem terapeuta se surpreendeu com as declarações, não reconhecia naquele discurso sua paciente que sempre falava da fisioterapia como algo importante. Ao dizer à fisioterapeuta da importância dada ao tratamento pela paciente, esta se sensibilizou e afirmou que criaria um grupo para um público específico e que Maria poderia ser incluída nele.

Estes acontecimentos marcaram um novo momento no tratamento. Era necessário buscar uma intervenção interdisciplinar. Segundo Mucida (2004), a velhice é um período da vida que nos escancara o real da castração e nossa cultura ocidental tenta tamponar a velhice e os velhos, atrelando a eles significantes como morte, improdutividade e inutilidade, na tentativa de manter quem ainda não é idoso "protegido". Velhice passa a se tornar álibi para tudo, principalmente se a ela conjuga-se doença. Era exatamente isso o que se podia observar nos discursos médicos; a situação vivida pela paciente estava sendo considerada como "mal da idade".

Passado um tempo, Maria começou a não comparecer aos atendimentos devido às fortes dores que estava sentindo na perna. $O$ período de férias escolares estava por vir, impossibilitando o acompanhamento do caso por um mês e meio. Findo esse período, tentou-se o contato com Maria para a retomada do tratamento, o que foi em vão, pois ela havia sido levada para o hospital. 
Causa indignação a gravidade a que o quadro clínico de Maria teve que chegar para que alguma providência pudesse ser tomada. Segundo seus familiares, depois de muitos gritos de dor na perna, ficou completamente paralisada e entrou numa espécie de coma, nos dizeres da família: "dormiu e não acordou mais".

O tratamento psicoterápico teria sua continuidade em outro setting, isto é, o hospital. Maria estava irreconhecível, apresentava aspecto cadavérico, estava extremamente magra, pálida, tinha muita dificuldade para respirar e não abria os olhos desde que fora internada. A primeira sessão nesse novo setting foi marcada pelo silêncio. Contudo, havia uma relação. Maria estava sendo legitimada enquanto sujeito, mesmo sendo incapaz de se comunicar.

$\mathrm{Na}$ semana seguinte, ela não se encontrava mais no setor de observação, havia sido transferida para a enfermaria, o que sinalizava uma melhora. Nesse setor, a concessão de permissão para atender Maria foi um tanto complexa; o contato foi feito com a psicóloga responsável pelo setor. Após muitas negociações, a profissional explicou que não era possível dar à paciente assistência psicológica, pois a mesma não estava falando e quando isso fosse possível ela mesma ofertaria o serviço. Contudo, a jovem terapeuta poderia freqüentar o hospital como visitante. Apesar do discurso explícito daquela profissional, a jovem terapeuta percebeu que existia permissão para continuar seu trabalho, e assim o fez.

Por duas semanas os atendimentos se resumiram em informar a Maria o que estava acontecendo a seu redor e fazer-lhe companhia. Certo dia, uma de suas filhas, que estava como acompanhante, relatou que a paciente, às vezes, apertava sua mão ou abria os olhos, mas que isso só ocorria quando Maria queria, e por isso se referia à sua mãe como "manhosa". Após esse relato, a jovem terapeuta começou a questionar sua prática. Pensou: "como a psicanálise, sendo uma prática do discurso, poderia ajudar aquele sujeito que não falava?”.

Freud (1914/1974), em "Sobre o narcisismo: uma introdução", afirma que quando alguém está com dor de dente há uma retirada da libido do mundo externo e, conseqüentemente, um retorno desta ao eu. Essa contribuição de Freud foi essencial, pois concluiu-se que semelhante processo estava ocorrendo com Maria. Ela investia sua libido apenas em objetos de seu interesse; de outra forma, manifestava seus progressos a quem valia a pena; por isso, em seu prontuário continuava o diagnóstico de rigidez corporal. Diante de tal conclusão, a jovem terapeuta pensou em provocar demanda, de modo que a paciente sentisse desejo de investir sua libido no mundo externo.

Na semana seguinte a essas reflexôes, Maria estava acompanhada pelo marido. A jovem terapeuta, após se paramentar conforme as instruçōes da enfermagem, começou a conversar com ele, mas com o intuito de fazer a paciente ouvir a 
conversa. Falava que já estava na hora de ela voltar à vida. Foi pedido para que ela abrisse os olhos e, aparentemente, nada aconteceu. Passados uns instantes, Maria começou a mexer as pernas e a jovem terapeuta encostou naquele corpo magro, meio rígido, investindo naquele sujeito ao dizer que estava ali, vendo seu esforço. A paciente continuou a se movimentar, mexeu as pernas e abriu os olhos. Foi um momento muito emocionante. Após abrir os olhos e demonstrar que estava consciente, com um olhar direcionado, começou a respirar com muita força e soltou um grunhido. A jovem terapeuta reforçou sua presença, disse que a estava ouvindo e vendo seus esforços, contudo era preciso calma. Além do A.V.C., que afetara dessa vez o outro lado do cérebro, a paciente apresentava pneumonia. Muito esforço poderia fazê-la engasgar com a secreção e isso poderia ser um complicador.

Em meio aos atendimentos, percebeu-se a necessidade de discutir o caso com o médico que acompanhava Maria. Ao ser indagado sobre o quadro clínico da paciente, o mesmo respondeu que o quadro neurológico inalterado era grave. Considerava que os danos físicos e cognitivos eram enormes, porém, como ela estava rígida, não era possível definir o grau da gravidade. Disse também que não tinha nenhuma restrição quanto ao tratamento psicológico, apesar de não acreditar que algo pudesse ser feito, uma vez que a paciente era incapaz de verbalizar; por fim, recomendou atendimento aos familiares. Ao ser perguntado sobre a pneumonia, disse que a família teria que aprender a lidar com esse quadro, pois ele seria uma constante na vida de Maria.

Na semana seguinte, a paciente estava acordada e, ao ver a jovem terapeuta, começou a gesticular com a boca, tentando falar, esforçando-se, mas o som não saía. Foi orientada a mostrar seus progressos aos médicos para que pudessem fazer uma avaliação mais adequada de seu quadro clínico. $\mathrm{O}$ fato de não conseguirem entendêla, em seus gestos, era angustiante, mas era possível ver sua sensível melhora.

No atendimento posterior, Maria conseguiu expressar um: "háááá!. Ficava gesticulando com a boca, só que desta vez com uma expressão de aflição. Ela ainda estava com pneumonia e tomando fortes antibióticos, mas, mesmo assim, havia informaçóes de que os médicos estavam pensando em lhe dar alta.

Nessa mesma semana, foi marcado um encontro com uma neuropsicóloga, a fim de discutir e pensar possíveis intervenções. Ao ouvir o caso, a profissional afirmou que a localização da lesão, ou seja, no lobo frontoparietal esquerdo, estava relacionada à área responsável pela linguagem. Como as duas lesões (a primeira no hemisfério direito e a segunda no esquerdo) afetaram a região da linguagem, além da dificuldade de elaborar pensamentos Maria teria também dificuldade de expressão. Por esse motivo, apesar de Maria se esforçar, não conseguia falar. Junto à neuropsicóloga foi traçado um planejamento de como seria possível intervir nesta nova fase. 
A jovem terapeuta ficou entusiasmada para poder colocar em prática as novas atividades. E foi então que, na semana seguinte, quando voltou ao hospital, recebeu a notícia que na manhã de domingo Maria havia falecido de uma parada cárdio-respiratória.

O tratamento havia chegado ao fim, o inevitável havia acontecido, o real nu e cru estava se apresentando por meio desta que escancara nossa finitude: a morte. Após tantos exercícios fisioterapêuticos, psicoterapia, recuperação de doenças, etc, é possível concluir que Maria, assim como seu pai e seu filho, morreu trabalhando; afinal, em seu corpo, ficou o retrato de seu trabalho.

A velhice é um assunto que tem sido estudado por diversas áreas do conhecimento. Estudos apontam que nos últimos 40 anos houve um intenso processo de concentração da população brasileira nos centros urbanos. Os imigrantes rurais buscam nas cidades oportunidades para melhorarem suas condições de vida. Contudo, ao chegarem, se instalam nas periferias, primeiro por falta de recursos financeiros e também porque os centros urbanos estão cada vez mais comerciais. Seguindo essa lógica e levando em consideração a perspectiva de vida aumentada em torno dos 70 anos, podemos concluir que a população idosa brasileira tende a aumentar, e esse aumento se dará principalmente nas periferias.

Somos um país de meia-idade com projeção de sermos, nos próximos 40 anos - conforme dados da ONU -, o país mais envelhecido do continente latinoamericano, considerando-se a população com mais de 60 anos no conjunto da população brasileira. Conforme dados do IBGE, existem 14 milhôes de idosos atualmente no Brasil. O número de idosos aumentou de 7,4\% em 1989 para 8,3\% em 1995 e chegou a 9,1 em 1999 (Mucida, 2004: 187).

Diante desse inevitável crescimento da população idosa, e levando em consideração o drama vivido por Maria, que é também o drama de vários idosos no Brasil, uma preocupação no que diz respeito aos serviços prestados a essa faixa etária se faz presente. Não raro, os idosos são considerados como pessoas mais próximas da morte e por isso não recebem tratamento e atendimento adequados.

No que diz respeito à saúde, Machado (2003) afirma que pouco mais de 7\% do orçamento é destinado aos serviços de Atenção Básica, que são responsáveis pelas medidas preventivas. Esse dado demonstra um descaso e uma incoerência em relação ao conceito de saúde da Organização Mundial de Saúde, que não a considera como ausência de doença. Esse investimento mínimo na Atenção Básica propicia a morosidade nas marcações de consultas, exames e também atendimentos que, se fossem realizados em um tempo hábil, evitariam que os usuários 
do SUS (Sistema Único de Saúde) precisassem dos serviços de média e alta complexidade, que são os serviços mais custeados. Nesse sentido, os princípios norteadores do SUS, tais como universalidade, integralidade e equidade, vão se tornando meros conceitos, e idosos que são também cidadãos nem sempre resistem à demora de um procedimento e/ou atendimento.

Diante dessa lamentável realidade, é necessário pensar o lugar do analista, principalmente num atendimento que se torna multidisciplinar, pois ele aparece como um profissional diferenciado no sentido de que, ao atender o sujeito, se interessa por ele e por suas questôes, sejam elas físicas e/ou psíquicas. O desejo do analista, enquanto lugar de endereçamento, por se constituir como Sujeito Suposto Saber, é o que vai diferenciar seu atendimento dos outros, uma vez que, indiferente das condições físicas do analisante, o analista apostará nele enquanto sujeito capaz de se relacionar melhor consigo mesmo e com o Outro, não importando quanto tempo de vida lhe reste.

\section{REFERÊNCIAS BIBLIOGRÁFICAS}

Abras, R. M. G. \& Sanches, N. R. A. (2004). O idoso e a família. Mimeo.

Freud, S. (1898). A sexualidade na etiologia da neurose. Obras completas, ESB, v. XII. Rio de Janeiro: Imago, 1976.

. (1912). A dinâmica da transferência. Obras completas, ESB, v. XII. Rio de Janeiro: Imago, 1969.

. (1914). Recordar, repetir e elaborar. Obras completas, ESB, v. XII. Rio de Janeiro: Imago, 1969.

. (1914). Sobre o narcisismo: uma introdução. Obras completas, ESB, v. XIV. Rio de Janeiro: Imago, 1974.

1974.

Machado, K. (2003). A Saúde que queremos e o SUS que temos. Revista RADIS: Comunicação em Saúde, 16. Disponível em <http://www.ensp.fiocruz.br/radis/pdf/radis_16.pdf>. Acesso em 02 mar. 2007.

Mucida, A. (2004). O sujeito não envelhece: psicanálise e velhice. Belo Horizonte: Autêntica.

Recebido em 15 de maio de 2007 Aceito para publicação em 17 de agosto de 2007 